\title{
IMPLEMENTANDO PRÁTICAS RESTAURATIVAS NAS E SCOLAS BRASILEIRAS COMO ESTRATÉGIA PARA A CONSTRUÇÃO DE UMA CULTURA DE PAZ
}

\author{
Implementing restorative practices in \\ Brazilian schools as a strategy for the \\ construction of a peace culture
}

\section{Patrícia Krieger Grossi ${ }^{[a]}$, Andréia Mendes dos Santos ${ }^{[b]}$, Simone Barros de O liveira ${ }^{[\mathrm{cl}}$, Camila da Silva Fabis ${ }^{[\mathrm{d}]}$}

[a]Professora Dra. do Programa de Pós-Graduação em Serviço Social da Pontifícia Universidade Católica do Rio Grande do Sul (PUCRS), Coordenadora do Núcleo de Estudos e Pesquisa em Violência NEPEVI, Pesquisadora do CNPq, Porto Alegre, RS BRASIL, e-mail: pkgrossi@ pucrs.br

${ }^{[b]}$ Psicóloga, Mestre e Doutora em Serviço Social pela Pontifícia Universidade Católica do Rio Grande do Sul (PUCRS), Pós-D outorado em Serviço Social na da Pontifícia Universidade Católica do Rio Grande do Sul (PUCRS), Integrante do NEPEVI, Porto Alegre, RS - Brasil, e-mail: andreiam72@ gmail.com

${ }^{[c]}$ D outoranda em Serviço Social da Pontifícia Universidade Católica do Rio G rande do Sul (PUCRS), Bolsista da CAPES, Integrante do NEPEVI. Professora da Faculdade de Serviço Social da Universidade Federal do Pampa (UNIPAMPA), São Borja, RS - Brasil, e-mail: siboliveira@yahoo.com.br

${ }^{[d]} G$ raduandado Curso dePsicopedagogiadaFaculdadedeEducação daPontifíciaUniversidade Católica do Rio Grande do Sul (PUCRS), Bolsista de Iniciação Científica do CNPq, Integrante do NEPEVI, Porto Alegre, RS - Brasil, e-mail: camilafabis@ hotmail.com

Rev. Diálogo Educ., Curitiba, v. 9, n. 28, p. 497-510, set./ dez. 2009 


\title{
Resumo
}

Este artigo tem por objetivo apresentar os resultados da pesquisa de avaliação e monitoramento de práticas restaurativas desenvolvidas em três escolas da rede pública e privada de Porto Alegre. Esta pesquisa é uma parceria da Faculdade de Serviço Social com a 3 a Vara do Juizado Regional da Infância e Juventude por meio do Projeto Justiça para 0 Século 21. Partimos de um diagnóstico situacional de cada escola para identificar expressões de violência e suas formas de enfrentamento através da aplicação de questionários a alunos e professores. A Justiça Restaurativa é uma abordagem inclusiva e colaborativa baseada nos valores de inclusão, pertença, solidariedade e escuta ativa que prevê a participação de alunos, professores, comunidade, família e rede de apoio nas situações de conflitos e violências visando à restauração das relações sociais. As práticas restaurativas vêm desconstruindo essa cultura de violência e promovendo a cultura de paz nas escolas. Conclui-se que 0 bullyingno ensino fundamental foi percebido como principal expressão de violência nas escolas participantes. Os círculos restaurativos realizados nas escolas contribuíram para a instauração de práticas dialógicas e afirmação de acordos que contemplaram as necessidades das vítimas e comunidade afetada. $90 \%$ das pessoas sentiram-se ouvidas e respeitadas, o que evidencia a necessidade contínua de fortalecimento dessas práticas no cotidiano escolar. Entre muitas das repercussões positivas do Projeto nas escolas, vale destacar a diminuição de encaminhamentos para o Serviço de O rientação Educacional (SOE), direção da instituição ou ao Departamento Estadual da Criança e do Adolescente e os sentimentos de segurança decorrentes da participação.

Palavras-chave: Práticas restaurativas. Escolas. Cultura de paz.

\begin{abstract}
This article has the objective to present the results of an evaluation and monitoring research of restorative practices developed in three schools of the private and public network of Porto Alegre. This research is a partnership between the Faculty of Social Work and the Third Childhood and Juvenile Justice Court through the Project Justice for the $21^{\text {st }}$ Century. We started from a situational diagnosis of each school to identify
\end{abstract}

Rev. Diálogo Educ., Curitiba, v. 9, n. 28, p. 497-510, set./ dez. 2009 
Implementando práticas restaurativas nas escolas brasileiras como estratégia para a construção de uma cultura de paz

expressions of violence and ways of coping through the application of questionnaires to students and teachers. Restorative Justice is an inclusive and collaborative approach based on the values of inclusion, belonging, solidarity and active hearing which seeks the participation of students, teachers, community, family and network of support in the situation of conflicts and violence, aiming the restoring of social relations. Restorative practices have been deconstructing this culture of violence and promoting a peace culture in the schools. It concludes that bullying in the elementary education is the main expression of violence in the participating schools. Restorative circles carried out in the schools have contributed for dialogical practices and the building of agreements that met the needs of the victims and the affected community. 90\% of the people felt listened and respected, which is an evidence of the continuing need of strengthening these practices in the school daily life. Among the many positive outcomes of the project in the schools it is worth to highlight the decrease in the referrals to Educational Guidance Services (SOE), direction of the institution or Children and Youth State Department (DECA) and feelings of safety that emerged from participation.

Keywords: Restorative practices. Schools. Culture of peace.

\section{INTRODUÇÃO}

Cultura de Paz inclui modos de vida, padrões, crenças, valores e comportamentos, bem como arranjos institucionais que promovem o bem-estar, bem como a igualdade que inclui o reconhecimento das diferenças (BOULDING , 2000 apud MILANI, 2003, p. 35).

O s referenciais teóricos da educação para a paz e direitos humanos (DE L REY ,2002; G UIMARÃE S, 2003, 2005; HICK S, 1999;JARE S, 2002; MALD ONAD O, 1997; MILANI, 2006; ORTEGA; RAYO, 1994) têm demonstrado ser eficaz naprevenção daviolência, possibilitando 0 aumento do diálogo, negociação, senso de responsabilidade e o protagonismo infanto-juvenil, reduzindo assim os riscos de vulnerabilidade social e penal.

Rev. Diálogo Educ., Curitiba, v. 9, n. 28, p. 497-510, set./ dez. 2009 
A justiça restaurativa também parte do princípio de que as relações podem ser restauradas baseadas nos valores de inclusão, pertença, solidariedade e escuta ativa, entre outros. A justiça restaurativa tem demonstrado ser um terreno fértil para a instauração de uma nova ótica nas relações, pautada pela reciprocidade, compromisso e corresponsabilidade. Esteirá incidir na prevenção da violência e diminuir os riscos de vulnerabilidade penal de adolescentes, instaurando novas formas de convivência.

As ideias sobre a Justiça Restaurativa (JR) têm sua origem há três décadas. Os primeiros registros foram verificados nos Estados Unidos em 1970, sob a forma de mediação entre réu e vítima, depois adotadas por outros países, com destaque para a experiência da Nova Zelândia. Também Chile, Argentina e Colômbia dão os primeiros passos em direção à Justiça Restaurativa.

A Nova Z elândia traz a história da Justiça Restaurativa a partir de necessidades de tribos indígenas, a começar na comunidade Maori. Por causa da falta de pertencimento que sentiam em relação ao sistema de justiça criminal e agências sociais. Achavam as punições muito severas aos jovens que cometiam atos infracionais. Neste pensamento o foco era que os jovens ficavam longe do convívio de suas famílias. "A justiça civilizada exige que os familiares do ofensor permaneçam ao seu lado durante rituais de justiça, compartilhando a vergonha pelo que aconteceu" (BRANCHER, 2006, p. 1).

No Brasil, mais especificamente em Porto Alegre, através da 3ํVIJ a Justiça Restaurativa tem seus primeiros passos em 2002. 0 Projeto de Justiça para o Século 21, idealizou a criação de um Projeto de Justiça Restaurativa. Projeto que tem sido desenvolvido desde agosto de 2004, quando um núcleo de estudos se iniciou na AJURIS - Escola de Magistratura. Hoje atuando como projeto piloto, vem sofrendo as devidas atualizações para melhor funcionamento, articulando as garantias de justiça previstas no Programa Nacional de Direitos Humanos.

A Justiça Restaurativa trabalha em uma perspectiva de foco na vítima, como forma de oportunizar sua restituição ante o fato ocorrido, bem como articular no mesmo processo de Justiça Restaurativa o ofensor ea comunidade. "Justiça Restaurativa é um processo através do qual todas as partes envolvidas em um ato que causou ofensa reúnem-se para decidir coletivamente como lidar com as circunstâncias decorrentes desse ato e suas implicações para o futuro" (BRANCHER, 2006, p. 21).

As experiências de justiça restaurativa nas escolas são recentes no Brasil, iniciando-se em Caetano do Sul, em São Paulo e, atualmente,

Rev. Diálogo Educ., Curitiba, v. 9, n. 28, p. 497-510, set./ dez. 2009 
Implementando práticas restaurativas nas escolas brasileiras como estratégia para a construção de uma cultura de paz

em Porto Alegre einterior do Rio G rande do Sul. No próximo item, será abordada a experiência de implementação de círculos restaurativos nas escolas como uma estratégia de resolução não-violenta de conflitos.

\section{Justiça restaurativa nas escolas}

A inserção do adolescente na escola é de extrema importância enquanto instância de ingresso no espaço público, uma vez que o ambiente escolar tem um potencial ímpar como referencial organizador, de conhecimento edemodelo ético paraestesjovens. Muitas vezes, entretanto, as escolas reproduzem práticas discriminatórias, excludentes e opressoras.

Um crescente contingente de jovens envolvidos em conflitos escolares são encaminhados pelas escolas para acompanhamento terapêutico ou para o Juizado da Infância e da Juventude na expectativa de resolutividade de um conjunto de questões complexas, fora do espaço escolar conforme foi constatado em pesquisas anteriores realizada com apoio da PUCRS; FAPERG S $(2003,2004)$ e em parceria com a $3^{\text {a }}$ Vara do Juizado da Infância e da Juventude.

A partir das pesquisas anteriores e mais recentemente, com 0 Projeto Justiça para o Século 21, surgiu a proposta de capacitação em justiça restaurativa para professores como uma possibilidade de criação de uma alternativa de ação coletiva ante os conflitos escolares (que muitas vezes são vistos como atos infracionais dos adolescentes). Partimos do pressuposto de que os conflitos são inerentes a todos os processos humanos, sendo sua problematicidade transferida para a forma como são enfrentados e resolvidos: violenta ou não violentamente. 0 conflito deixa de ser encarado como o oposto da paz para ser visto como um dos modos de existência em e da sociedade, seja pela divergência deinteresses e pela diferença de situação que isso supõe, seja pela posição ocupada na sociedade, pela disposição de recursos e pelo partido que se toma em questões de disputa (G UIMARÃES, 2003).

Namedidaem quepudermos avaliaretestaro guiadeprocedimentos paraainstauração doscírculosrestaurativos, poderemosadaptá-lo eaperfeiçoálo para a realidade das escolas, tornando-o assim mais efetivo.

As iniciativas voltadas para a educação para a paz e justiça restaurativa incorporam valores essenciais para a cultura democrática como participação, diálogo, igualdade, justiça social, respeito à diversidade e aos direitos humanos, indo ao encontro do projeto ético-político da nossa profissão.

Rev. Diálogo Educ., Curitiba, v. 9, n. 28, p. 497-510, set./ dez. 2009 
O s valores fundamentais são a participação de todos, vítima, ofensor e comunidade de forma ativa no processo de Justiça Restaurativa, exercendo a capacidade de relação entre todos sem necessariamente depender de um profissional treinado para chegarem a um acordo. 0 respeito como valor, pois "todos os seres humanos tem valor igual e inerente, independente de suas ações, boas ou más" (MARSHALL; BOYARD ; BOWEN, 2005). Na Justiça Restaurativa todos são dignos de respeito, devendo este ser mútuo entre as partes.

A honestidade, todos os envolvidos devem ser "transparentes" nos seus sentimentos quando estão em um processo de Justiça Restaurativa. Na Justiça Restaurativa, "a verdade produz mais que a elucidação dos fatos e o estabelecimento da culpa dentro dos parâmetros estritamente legais; ela requer que as pessoas falem abertamente sobre sua experiência relativa à transgressão." D evido à Justiça Restaurativa não fazer diferenças entre classe social, gênero, cultura, etc, a humildade é trabalhada como valor, por ser através dela que se "reconhece a condição humana universal, capacitando vítima e ofensor a descobrirem" (BRANCHER, 2006, p. 18) que são seres humanos muitas vezes com mais coisas em comum do que possam imaginar.

Interconexão como valor, referindo a relação que vítima e ofensor estabelecem mesmo antes do ato; relações que foram estabelecidas pela sociedade, "naqual todos estão interligados porumaredederelacionamento. A sociedade compartilha responsabilidade por seus membros e pela existência de crimes, e há uma responsabilidade compartilhada para ajudar a restaurar as vítimas e reintegrar os ofensores" (BRANCHER, 2006, p. 18).

A Justiça Restaurativa traz também em seus valores a responsabilidade, o empoderamento e a esperança. A responsabilidade emerge através da busca do ofensor pela restauração do ato que causou, ou seja, ele deverá se responsabilizar pelo seu ato, uma vez que causou dano à outra pessoa. $\mathrm{O}$ empoderamento como valor é representado pela vítima quando a ela é devolvido os poderes perdidos no ato. As vítimas têm papel ativo para determinar quais são as suas necessidades e como estas devem ser satisfeitas. Isto também dá poder ao ofensor de responsabilizar-se por suas ofensas. E , por fim, a esperança como valor; a Justiça Restaurativa alimenta a esperança de reparação para as vítimas, transformando a dor rumo a uma perspectiva de relação mais civilizatória.

A Justiça Restaurativa é um campo em expansão para atuar no desenvolvimento de modelos relacionados às políticas públicas da infância e da juventude; com ênfase no Estatuto da Criança e do Adolescente que visa ao atendimento integrado do adolescente no

Rev. Diálogo Educ., Curitiba, v. 9, n. 28, p. 497-510, set./ dez. 2009 
Implementando práticas restaurativas nas escolas brasileiras como estratégia para a construção de uma cultura de paz

Sistema de Justiça e as escolas têm criado espaços para o exercício desta prática dialógica e emancipatória na concepção de uma educação não mais voltada somente para o conteúdo, mas uma educação voltada para a cidadania, para a ressignificação de práticas e saberes docentes.

\section{0 processo de implementação dos círculos restaurativos nas escolas - o piloto e a pesquisa}

O s critérios para a seleção das três escolas que fizeram parte do projeto-piloto foram:

a) ser de natureza diversa (uma estadual, uma municipal e uma particular;

b) ter turno diurno;

c) ter disponibilidade e interesse na proposta de aplicação de círculos restaurativos;

d) ter disponibilidade de tempo na carga horária do docente para a capacitação e execução dos círculos restaurativos;

e) não possuir experiência em práticas restaurativas;

f) oferecer ensino médio;

g) ter participado do seminário de abertura das atividades do Projeto Justiça para o Século 21.

Foram avaliados o clima escolar, as expressões de violência, forma de resolução de conflitos antes e após a instauração dos círculos restaurativos para avaliar o seu alcance e efetividade na prevenção da violência e grau de satisfação entre os envolvidos. A próxima etapa previa a capacitação de cinco pessoas, designadas por cadauma das escolas, e que atuariam como referências para a comunidade interna em relação às iniciativas do projeto, bem como comporiam o grupo mais amplo de referência do piloto junto às demais escolas e ao projeto Justiça para 0 Século 21. Essas referências deveriam participar das oficinas de capacitação iniciais com D ominic Barter, capacitador oficial do projeto, com duração de três dias, além de supervisões mensais, no período entre abril e novembro de 2007. No total, foram capacitados 21 representantes de 4 escolas.Uma escola foi adicionada depois de uma decisão coletiva do grupo que ficou sensibilizado com as situações de violência que estavam vivenciando e o interesse demonstrado na superação daquela realidade. Houve também a solicitação de uma escola para a inclusão de mais um

Rev. Diálogo Educ., Curitiba, v. 9, n. 28, p. 497-510, set./ dez. 2009 
professor, visto que, dessa forma, ficaria contemplada a estrutura escolar de acordo com os níveis de ensino oferecidos.

Também foi realizado um encontro de sensibilização para 0 projeto em cada escola, estendido à comunidade escolar, incluindo professores, funcionários, alunos e aberto à participação dos pais. Em uma das escolas, esse encontro de sensibilização ficou restrito somente aos professores, sendo divulgado para os pais através do jornal da escola em momento posterior.

A pesquisa, por caracterizar-se como sendo do tipo de pesquisaação, desde o início envolveu mecanismos de incentivo e apoio à coletivização de iniciativas criativas, autônomas e responsáveis em cada escola, realizando-se sistemáticas reuniões de planejamento, avaliação e reflexão com seus grupos de referência. $\mathrm{Na}$ etapa de aproximação, foi realizado um diagnóstico situacional ${ }^{1} \mathrm{DS}$, que forneceu subsídios em relação ao momento inicial em queas escolas encontravam-se, identificando zonas de maiores tensões e, possivelmente, fontes de geração de conflitos.

\section{A pesquisa-ação e a corresponsabilidade na sensibilização da comunidade escolar}

Priorizando a sensibilização da comunidade escolar permanentemente, 242 professores foram sujeitos da pesquisa. A participação deu-se através de questionário padrão, respondido individualmente pelo corpo docente da escola e sem identificação pessoal. Não foi possível o alcance de $100 \%$ da meta em relação aos professores. D urante a aplicação do instrumento, intercorrências, como a paralisação dos profissionais municipários de Porto Alegre, falta de professores nas escolas ea negação em participardo estudo, foram levadas em consideração.

A opinião dos professores teve ampla escuta através do questionário. Porém, a participação dos docentes não ficou restrita ao instrumento, também sendo acolhida e considerada a sua fala na interação cotidiana com a equipe de pesquisa e comportamentos observados na escola. Em relação à compreensão do fenômeno de conflitos e agressões no âmbito escolar, foi observado que a temática vem preocupando os professores de Porto Alegre. Mais de 95\% dos docentes expressaram

1 Agradecemos a participação dos alunos de graduação da FSS da PUCRS, Ana Maria Peçanha, Taís Cunha da Silva, Luciana Matter e Jacqueline Carbonari; e os auxiliares da pesquisa associados ao NEPEVI, Luciana Kalil dos Santos e Luciane Bueira Loureiro no processo de coleta de dados e acompanhamento das 4 escolas-piloto.

Rev. Diálogo Educ., Curitiba, v. 9, n. 28, p. 497-510, set./ dez. 2009 
Implementando práticas restaurativas nas escolas brasileiras como estratégia para a construção de uma cultura de paz

como muito importante ou bastante importante esses problemas nas comunidades escolares. Um fator que justifica essa preocupação, bem como demonstra a situação das instituições de ensino em relação à questão da disciplina, é a estimativa de tempo, atribuída pelos educadores, para a abordagem de temas relacionados com disciplina e resolução de conflitos, conforme demonstra a tabela a seguir:

TABELA 1 - Professores: situação atual em relação aos conflitos. Projeto de Pesquisa Justiça para o Século 21 - Porto Alegre, 2007

\begin{tabular}{lcc}
\hline $\begin{array}{c}\text { Porcentagem aproximada de tempo escolar investida em temas } \\
\text { relacionados com a disciplina e os conflitos }(\mathbf{N}=\mathbf{2 4 2})\end{array}$ \\
\hline Menos do que 20\% & 74 & 30 \\
Entre 21 e 40\% & 83 & 24,2 \\
Entre 41\% e 60\% & 48 & 19,8 \\
Mais do que 60\% & 29 & 11,9 \\
Não tenho problemas de disciplina & 08 & 3,3 \\
\hline
\end{tabular}

Para eles, $100 \%$ das agressões possuem cunho verbal, isto é, são insultos, ameaças e xingamentos. Em 86,3\% dos casos, essas ofensas desencadeiam também agressões físicas. O utras formas de agressões, como isolamento, rejeição e pressão psicológica (rir de alguém, importunar) corresponderam a 77,7\% ; chantagens, roubos e destruição, 20,6\%; e cerca de 5,3\% dos professores não identificam agressões relevantes na escola. Foram identificados os seguintes fatores motivadores para as agressões, segundo a questão anterior e em ordem de prevalência (admitia-se resposta múltipla):

TABELA 2 - Fatores Motivadores da Agressão entre os alunos na Perspectiva dos Professores. Projeto de Pesquisa Justiça para o Século 21 - Porto Alegre, 2007

\begin{tabular}{ll}
\hline MOTIVAÇÃO PARA A AGRESSÃo & $\%$ \\
\hline Personalidade, caráter & 79,3 \\
Status, modelo social & 38 \\
Racismo, intolerância & 33,8 \\
G ênero & 23,9 \\
Outros fatores & 9,9 \\
Quase não há agressões & 5,3 \\
\hline
\end{tabular}

Rev. Diálogo Educ., Curitiba, v. 9, n. 28, p. 497-510, set./ dez. 2009 
Em relação aos locais, na escola em que ocorrem com maior frequência as agressões e as intimidações entre os alunos (admitia-se resposta múltipla), 205 professores levantaram as seguintes respostas: 0 local de maior incidência de conflitos é o recreio/ pátio (86,3\%). Os horários de entrada e de saída do colégio $(47,3 \%)$ cediam espaço para confrontos; os corredores, principalmente durante os intervalos das aulas, correspondem ao terceiro lugar, com 43,9\% das ocorrências; e $40 \%$ ocorrem durante as aulas, na própria sala. Cerca de $18 \%$ dos professores não identificam locais, considerando que não existem espaços predeterminados para a ocorrência. E outros (4,8\%) avaliam que os conflitos se dão nos serviços especializados da escola.

Três escolas do piloto participaram da pesquisa na etapa referente àopinião dosalunos do ensino fundamental. Foi realizadaumaamostragem, selecionando alunos de $4^{\mathrm{a}}$ e $7^{\mathrm{a}}$ série, correspondendo 113 alunos ao total. Mais de 25\% dessas crianças apontaram haver momentos em que não se sentem bem na escola. Q uase 10\% dessas declaram sentirem-se muito mal no ambiente escolar. Frise-se que a principal causa do medo são os próprios colegas $(12,8 \%)$, sendo que mais de $10 \%$ dos alunos admitem sentir medo de ir à escola, mas não revelam o motivo de tal sentimento; 8,9\% apontam o professor como causa do temor; e 5\% definem a tarefa de aula como a principal dificuldade.

O bserva-se que, na maioria das vezes, os meninos $(\mathrm{N}=42)$ são os autores das agressões, mas, entre as meninas, o fenômeno também é expressivo $(\mathrm{N}=30)$. A demais, há a possibilidade de ocorrer conflitos envolvendo os dois gêneros $(\mathrm{N}=13)$. A sala de aula tem sido palco da maior parte das ofensas, superando pátio, banheiros e horários de entrada e saída, remetendo a lógica de que a presença do professor (ou responsável pela turma) não representa ameaça ao aluno autor.

\section{A experiência de círculos restaurativos nas escolas-piloto}

Nesse período de acompanhamento do piloto nas escolas, foram realizados 9 pré-círculos, 7 círculos e 6 pós-círculos. Um dos alunos, participante do círculo restaurativo em uma escola municipal, na condição de autor, cujo fato consistia em passar o período todo circulando em sala de aula, passou a ter um melhor desempenho escolar, que refletiu numa diminuição de suaagressividade com os demais colegas enum envolvimento nas tarefas propostas pela professora por meio de maior participação da família na escola, bem como de uma maior atenção de sua professora.

Rev. Diálogo Educ., Curitiba, v. 9, n. 28, p. 497-510, set./ dez. 2009 
Implementando práticas restaurativas nas escolas brasileiras como estratégia para a construção de uma cultura de paz

Em uma das escolas estaduais, uma das meninas que participou de dois círculos restaurativos, na condição de autora, cujo fato era a agressão física contra colegas, passou a não exercer mais esse tipo de conduta, inseriu-se em um grupo de dança na escola e tornou-se líder de turma, deixando de ser vista como uma "liderança negativa". Frisese que a família passou a ser assistida pela rede de apoio da comunidade. Em outro círculo, o fato originário referia-se à negativa de diálogo entre duas colegas da mesma classe da $6^{\underline{a}}$ série. A través da realização do pré-círculo e do círculo foi possível, efetivamente, às pessoas envolvidas refletirem sobre as causas-raiz do fato, que remetiam a um problema anterior, e que, depois de esclarecido, possibilitou melhor qualidade nas relações das meninas, incluindo encontros fora do ambiente escolar no período do pós-círculo.

Esses são apenas alguns exemplos da resolutividade do processo restaurativo dos círculos e da mudança no clima escolar. A importância da participação em círculos restaurativos, enfocando conflitos entre docente e discente, revelou uma intencionalidade: a do professor, predisposto a acolher 0 aluno, e a do aluno, predisposto a ouvir 0 professor. Nesse processo, ocorre um alongamento do olhar do educador, que passa a ver o aluno não mais como um "aluno-problema", mas sim como uma pessoa com necessidades, desejos, carências e, ao mesmo tempo, com responsabilidades ao estabelecer um acordo em comum que atenda as necessidades de todos envolvidos.

\section{CONSIDERAÇÕES FINAIS}

As escolas tiveram ampla liberdade para melhor estruturarem a implementação das práticas restaurativas e fortalecerem estratégias de difusão da cultura de paz, previstas como objetivos do piloto. A realização de grupos de estudos, com a participação dos professores que integraram as oficinas de capacitação e tornaram-se referências nas escolas, revelou-se essencial para o sucesso no desenvolvimento das ações nas escolas. Cadainstituição organizou-se levando em consideração o tempo disponível, a carga horária dos professores e a disponibilidade para a realização das atividades. Entre as ações promovidas por elas para a implementação, que particularizam condições que favorecem um processo acolhedor para o desenvolvimento da cultura de paz, de estratégias de resolução não violenta de conflitos e de introdução de práticas restaurativas, destacam-se:

Rev. Diálogo Educ., Curitiba, v. 9, n. 28, p. 497-510, set./ dez. 2009 
a) capacidade de mobilização da comunidade escolar para além dos professores e alunos. Essa capacidade foi materializada especialmente em dois eventos. Primeiro, pela realização de uma palestra intitulada Comunicação não violenta eCultura de Paz: Pais \& Filhos - encontros e desencontros. Essa iniciativa de uma das escolas oportunizou ampla divulgação das iniciativas do piloto, alcançando cerca de 3.000 famílias que compõem-na. 0 segundo evento, na mesma linha, foi a divulgação, no jornal de uma das escolas, com tiragem media de 3.000 exemplares, de matériacontendo esclarecimentos sobre o piloto, a pesquisa e notas sobre cultura de paz e comunicação não violenta;

b) abertura para o permanente autoquestionamento e compromisso com o protagonismo pelo processo. 0 acolhimento das instituições em relação ao grupo de pesquisadores da Faculdade de Serviço Social da PUCRS, no que se refere ao acompanhamento das atividades desenvolvidas pelas escolas, bem como na realização de encontros-reuniões sistemáticas;

c) estratégias criativas de autossupervisão. D entre essas estratégias, destaca-se a simulação de círculos restaurativos, denominadas oficinas de práticas restaurativas, que concorreram para a divulgação, esclarecimento, discussão e implementação das práticas restaurativas nas escolas;

d) apoio institucional erespaldo da Secretariade E ducação. Esse aspecto também é destacado como atributo de processo que a pesquisa identificou. Em uma das escolas, houve a participação mais ativa da SEDUC, através da representanteinstitucional do projeto, Nelnie Lorenzoni, que realizou duas oficinas sobre valores e comunicação não violenta, baseadas no referencial de Marshall Rosemberg, para todo o corpo docente;

e) auto-organização como qualidade de processo. A organização escolar em relação a carências e deficiências das instituições envolvidas foi decorrência do processo e também revela qualidades particulares desse. Mais como consequência do que objetivo de fato, os grupos de referência aproximaram-se das instâncias gestoras 
Implementando práticas restaurativas nas escolas brasileiras como estratégia para a construção de uma cultura de paz

correspondentes para discussão de dificuldades que também serviam como fontes geradoras de conflitos, como a redução do quadro funcional decorrente de afastamentos de licença-saúde, faltas não justificadas, a estruturadeficitária, problemas de relacionamento entre o corpo docente e insatisfação dos funcionários, principalmente em relação à remuneração;

f) adifusão daculturadepaz. Essefoi um doscomponentes fortes do projeto, pois o estudo eaaplicação daabordagem dacomunicação não violentapermitiram aos professores ficarem atentos para a importância de observar os fatos sem avaliar, revendo os própriosvalores ejuízos devalor, uma vez que o "objetivo daCNV não émudar as pessoas e seu comportamento para conseguir o que queremos, mas sim, estabelecer relacionamentos baseados em honestidade e empatia, que acabarão atendendo as necessidades de todos" (RO SENBERG, 2006, p. 127). Em algumas escolas, foram construídos espaços que receberam denominações diversas, como "grupo de estudos da comunicação não violenta”, e ampliaram-se para outros professores interessados na proposta, além das pessoas referências do projeto.

\section{REFERÊNCIAS}

BRANCHER, L. Manual de práticas restaurativas. Brasília: PNUD, 2006. v. 1.

BRASIL. Lei n. 8.069, de 13 de julho de 1990. Dispõe sobre o estatuto da criança e do adolescente, eda outras providencias. Diánio Oficial [da] República Federativa do Brasil, Poder Legislativo, Brasília, DF, 16 jul. 1900. p. 13563. Disponível em: < http:/ / www6.senado.gov.br/ legislacao/ ListaTextoIntegral.action?id=75648>. Acesso em: 23 jul. 2009.

GUIMARÃES, M. R. Aprender a educar para a paz. Porto Alegre: EDUCAPAZ, 2003.

Educação para paz: sentidos e dilemas. Caxias do Sul, RS: EDUCS, 2005.

HICKS, D. (Org.). Educación para la paz: cuestiones, principios y practica en el aula. 2. ed. Madrid: Ministerio de Educación y Cultura, 1999.

JARES, X. Educação para a paz: sua teoria e sua prática. Porto Alegre:Artmed, 2002.

Rev. Diálogo Educ., Curitiba, v. 9, n. 28, p. 497-510, set./ dez. 2009 
MALD O NAD O, M. T. Os construtores da paz: caminhos para a prevenção da violência. São Paulo: Moderna, 1997.

MARSHALL, C.; BOYACK, J;; BOWEN, H. Como a justiça restaurativa assegura a boa prática: uma abordagem baseada em Valores. In: SLAKMO N, C. R.; DeVITTO, R. C. P.; PINTO, R. S. G. (O rg.). Justiça restaurativa. Brasilia, DF: Ministério da Justiça e Programa das Nações Unidas para o D esenvolvimento, 2005.

MILANI, F. M. Cultura de paz e ambiência saudáveis em contextos educacionais: a emergência do adolescente protagonista. Educação, Porto Alegre, ano 29, n. 2, p. 369-386, 2006.

ORTEGA, R.; DEL REY, R. Estratégias educativas para a prevenção da violência. Brasília: Unesco, 2002.

RAYO, J. T. E ducação em direitos humanos: rumo a uma perspectiva global. 2. ed. Porto Alegre: Artmed, 1994.

ROSENBERG, M. B. Comunicação não-violenta: técnicas para aprimorar relacionamentos pessoais e profissionais. São Paulo: Agora, 2006.

Recebido: 20/ 03/ 2009

Recived 03/ 20/ 2009

Aprovado: 11/ 04/ 2009

Approved: 04/ 11/ 2009

Revisado: 16/ 09/ 2009

Reviened 09/ 16/ 2009

Rev. Diálogo Educ., Curitiba, v. 9, n. 28, p. 497-510, set./ dez. 2009 